\title{
Uterine Compression Sutures as an Effective Treatment for Postpartum Hemorrhage: Case Series
}

\author{
Nihal Al Riyami, M.D.,',2 Dini Hui, M.D., 1,2 Elaine Herer, M.D.,' \\ and Ori Nevo, M.D. ${ }^{1,2}$
}

We evaluated the role of uterine compression sutures as a conservative treatment for postpartum hemorrhage (PPH) after failed medical treatment. We retrospectively reviewed the charts of all patients who delivered between 2003 and 2009 at a single tertiary care center and who underwent uterine compression sutures for PPH. Twelve women had uterine compression sutures for PPH. The mean age of the patients was $36.3 \pm 5.2$ years. The mean gestational age at delivery was $37.7 \pm 2.0$ weeks, and the average estimated blood loss was $2.1 \pm 1.1 \mathrm{~L}$. The mean procedure time to perform the uterine compression sutures was $9.3 \pm 2.8$ minutes. The success rate of compression sutures was $92 \%$ with only one failure resulting in a hysterectomy. Uterine compression sutures are an effective method for the treatment of $\mathrm{PPH}$, thus avoiding hysterectomy and preserving potential fertility.

KEYWORDS: Fertility, postpartum hemorrhage, uterine compression sutures

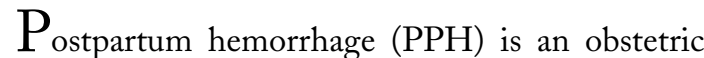
emergency that occurs in 1 to $5 \%$ of both vaginal and cesarean deliveries. ${ }^{1,2} \mathrm{PPH}$ is a major cause of maternal morbidity, with sequela such as hemodynamic shock, renal failure, acute respiratory distress syndrome, coagulopathy, and Sheehan's syndrome. PPH is also one of the top five causes of maternal mortality in both developed and developing countries, although the absolute risk of death is much lower in the former than the latter ( 1 in 100,000 versus 1 in 1000 births). ${ }^{2}$

$\mathrm{PPH}$ is defined as estimated blood loss of $\geq 500 \mathrm{~mL}$ after vaginal delivery or $\geq 1000 \mathrm{~mL}$ after cesarean section. ${ }^{3,4}$ Another definition of $\mathrm{PPH}$ is a reduction in the patient's hematocrit level of more than
$10 \%$ compared with the prenatal value or blood loss causing hemodynamic instability of sufficient degree to require blood transfusion. ${ }^{5,6}$

Uterine atony is the most common cause of $\mathrm{PPH}$, accounting for $80 \%$ of $\mathrm{PPH}$ cases. ${ }^{7,8}$ Other causes include trauma-related bleeding that can be due to lacerations (perineal, vaginal, cervical, uterine), incisions (hysterectomy, episiotomy), or uterine rupture. Lacerations of the birth canal and uterus are more common after instrumental delivery. Acquired and congenital bleeding diatheses may be associated with thrombocytopenia and/or hemostatic defects (e.g., HELLP syndrome [hemolysis, elevated liver enzymes, and low platelet count], abruptio placentae, fetal demise, amniotic fluid embolism, and

\footnotetext{
${ }^{1}$ Department of Obstetrics and Gynecology; ${ }^{2}$ Division of MaternalFetal Medicine, Sunnybrook, Health Sciences Centre, University of Toronto, Toronto, Canada.

Address for correspondence and reprint requests: Nihal Al Riyami, M.D., Division of Maternal Fetal Medicine, Sunnybrook Health Sciences Center, Obstetrics and Gynecology, 60 Grosvenor Street, suite 630, Toronto, Ontario M5S 1B6, Canada (e-mail: drriyami@ hotmail.com).
}

Am J Perinatol Rep 2011;1:47-52. Copyright (C) 2011 by Thieme Medical Publishers, Inc., 333 Seventh Avenue, New York, NY 10001, USA. Tel: +1(212) 584-4662.

Received: November 25, 2010. Accepted after revision: January 22, 2011. Published online: June 9, 2011.

DOI: http://dx.doi.org/10.1055/s-0031-1280570.

ISSN 2157-6998. 
sepsis). Coagulopathy of massive blood loss may develop in women with severe hemorrhage.

The treatment of $\mathrm{PPH}$ depends on the underlying cause and includes both routine prophylactic measures during the time of delivery and additional treatment in cases of PPH. Prophylactic strategies, including the administration of oxytocin after delivery, have been shown to reduce the incidence of $\mathrm{PPH}$ from as much as $18 \%$ to around 5 to $8 \% .{ }^{9}$ Treatment of $\mathrm{PPH}$ due to uterine atony comprises medical and noninvasive treatment such as bimanual compression of the uterus, uterotonic medications, and placement of intrauterine balloon. Failure of medical treatment occurs in less than $1 \%$ of patients, ${ }^{10}$ and surgical methods combined with resuscitative measures are usually used when conservative treatment fails. Hysterectomy is considered to be the final option when all conservative and surgical treatments fail. Postpartum hysterectomy not only leads to infertility but may also be associated with surgical difficulties and further complications including injury to adjacent organs such as bladder and ureters and infection. Surgical techniques that are aimed to preserve the uterus have been developed over the past 10 years. The procedure involves uterine compression sutures by bracelike suturing as was reported by B-Lynch ${ }^{11}$ or U-type sutures. ${ }^{5}$ Uterine compression sutures have been reported as an effective method in treating PPH and thus avoiding hysterectomy. However, the reported experience with this method is limited.

The aim of our study was to report our experience with uterine compression sutures and evaluate the role of uterine compression sutures in treating patients with $\mathrm{PPH}$ and failed conservative treatment.

\section{MATERIALS AND METHODS}

The study was approved by the local Research Ethics Board. We performed a chart review of all cases of PPH that occurred between January 2003 and July 2009 in Sunnybrook Health Sciences Centre, which is a tertiary center with $\sim 3500$ deliveries per year. We included all women who underwent uterine compression sutures after delivery during the study period. We did not exclude any patient from this report. There were around 25,000 deliveries during the study period. Twelve women with $\mathrm{PPH}$ due to uterine atony who were treated with uterine compression sutures after failing to respond to conservative measures were identified. Clinical, laboratory, surgical and follow-up data were extracted from the charts and by contacting the relevant physicians.

The procedure was performed in the face of persistent uterine atony, refractory to uterine massage, oxytocin infusion and bolus, methylergonovine or carboprost tromethamine (Hemabate) injections using the maximum dosage.

\section{RESULTS}

Maternal characteristics are summarized in Table 1. The mean age of the women was 36.3 years (range 30 to 47 years). Mean hemoglobin concentration before delivery was $12.3 \pm 1.3 \mathrm{~g} / \mathrm{dL}$ and after delivery was $8.4 \pm 1.8 \mathrm{~g} / \mathrm{dL}$. All women delivered by cesarean section with a mean gestational age of $37.7 \pm 2.0$ weeks. The procedure was not performed in women who had $\mathrm{PPH}$ and delivered vaginally. The intraoperative details are summarized in Table 2 .

Three women had B-Lynch sutures and the rest had U-type sutures compressing the anterior and posterior wall of the uterus. The mean operative time for performing the compression sutures was 9 minutes (range 5 to 14 minutes).

Cesarean section had been performed through a Pfannenstiel incision in all women. The uterus was exteriorized and the cavity thoroughly explored. If the bleeding was diffuse and no distinct source was identified, the uterus was compressed to assess whether the uterine compression sutures would be successful. The suture material was No. 1 Biosyn (Sichuan Biosyn Pharmaceutical Co., LTD, Deyang City, China) or 2/0 Caprosyn (Covidien, Mansfield, MA). Several sutures were inserted until the bleeding was controlled either with the B-Lynch technique or the $U$ suture technique. ${ }^{5}$ Two patients had a unilateral uterine artery ligation in addition to the compression sutures to control bleeding secondary to iatrogenic laceration during traumatic delivery. All the women tolerated the procedure well. Three women were transfused with packed red blood cells (ranging from 2 to $20 \mathrm{U}$ ). The procedure failed and resulted in a hysterectomy in one woman. This woman was a 32-year-old primiparous who had failed trial of forceps and therefore had an urgent cesarean section. She received $20 \mathrm{U}$ packed red blood cells, $10 \mathrm{U}$ platelets, $9 \mathrm{U}$ fresh frozen plasma, and $4 \mathrm{U}$ cryoprecipitate. All measures, including B-Lynch sutures and uterine packing, were performed and failed. There were no immediate postoperative

Table 1 Maternal Demographics and Characteristics

\begin{tabular}{ll}
\hline Characteristics & Mean (n=12) \\
\hline Age $(y)$ & $36.3 \pm 5.2$ \\
Gravidity & $3.5 \pm 1.8$ \\
Nullipara $(n)$ & $8(67 \%)$ \\
Singleton $(n)$ & $5(42 \%)$ \\
Twins $(n, \%)$ & $6(50 \%)$ \\
Triplets $(n, \%)$ & $1(8 \%)$ \\
Mode of delivery & \\
Elective cesarean section & $6(50 \%)$ \\
Emergency cesarean section & $6(50 \%)$ \\
Gestational age at delivery (wk) & $37.7 \pm 2.0$ \\
Estimated blood loss (L) & $2.1 \pm 1.1$ \\
Predelivery hemoglobin $(\mathrm{g} / \mathrm{dL})$ & $12.3 \pm 1.3$ \\
Postdelivery hemoglobin $(\mathrm{g} / \mathrm{dL})$ & $8.4 \pm 1.8$ \\
\hline
\end{tabular}


Table 2 Characteristics of Women and Intraoperative Details

\begin{tabular}{lllllllll}
\hline $\begin{array}{l}\text { Case } \\
\text { No. }\end{array}$ & $\begin{array}{l}\text { Maternal } \\
\text { Age }\end{array}$ & Parity & GA & $\begin{array}{l}\text { Mode of } \\
\text { Delivery }\end{array}$ & $\begin{array}{l}\text { Concomitant } \\
\text { Conditions }\end{array}$ & $\begin{array}{l}\text { EBL } \\
\text { (L) }\end{array}$ & $\begin{array}{l}\text { Intraoperative } \\
\text { Transfusions (U) }\end{array}$ & Other Procedures \\
\hline 1 & 30 & 0 & 35 & C/S & Triples/Bicor Ut & 3 & 4 PRBC & U-type \\
2 & 32 & 0 & 39 & C/S & Failed forceps & 5 & 20 PRBC, 9 FFP 4 Cryo, & B Lynch \\
hysterectomy \\
U-type
\end{tabular}

Bicor Ut, bicornuate uterus; C/S, cesarean section; Cryo, cryoprecipitate; EBL, estimated blood loss; FFP, fresh frozen plasma; GA, gestational age; L, left; Plts, platelets; PRBC, packed red blood cells; R, right; uterine a lig, uterine artery ligation.

complications in all women, and the mean discharge time was $5.1 \pm 1.4$ days.

Long-term follow-up revealed complications in two patients. One patient had myometrial necrosis identified in a subsequent pregnancy. This was a 32 -year-old woman who underwent a cesarean section in her first pregnancy for failure to progress. One B-Lynch suture and two $\mathrm{Cho}^{12}$ sutures were used to control PPH. In the subsequent pregnancy, a large triangular myometrial defect was identified in the midanterior uterine wall, and two smaller defects in the posterior wall were noted during her elective repeat cesarean section. The second patient was treated by B-Lynch suture due to persistent uterine atony in her first delivery. In her second pregnancy, she presented at 32 weeks with signs of preterm labor and was delivered by urgent cesarean section due to hemodynamic shock caused by uterine rupture.

\section{DISCUSSION}

$\mathrm{PPH}$ is a life threatening condition. Fortunately, medical management of $\mathrm{PPH}$ is quite successful, and surgical interventions are not needed in the vast majority of the cases. However, when surgical interventions are required, a procedure that is efficient and preserves fertility is preferable. We report our experience with uterine compression sutures that were developed as uterinesalvaging procedures for the treatment of $\mathrm{PPH}$. Most of our patients $(92 \%)$ responded well to the procedure and no other surgical interventions were needed. The procedure was performed by various physicians. Two patients had partial uterine wall necrosis or uterine rupture after B-Lynch suture, and one had a uterine artery ligation in addition to compression sutures. None of the more simple U-shaped sutures was associated with long-term complications.

Several methods have been described for the treatment of PPH secondary to uterine atony including mechanical and pharmacological methods. If bleeding persists despite these measures, surgical interventions such as uterine artery ligation, hypogastric or internal artery ligation, and finally hysterectomy ${ }^{13}$ may be performed.

In 1997, B-Lynch et al described a highly effective surgical technique for the control of postpartum bleeding in five women with $\mathrm{PPH}$ : compressing the uterus with two longitudinal sutures along its long axis and preventing the uterus from relaxing and filling with blood. ${ }^{11}$ Other techniques for uterine compression sutures have been reported in small case series., ${ }^{5,14-16}$ Hayman et al described placement of two to four vertical compression sutures from the anterior uterine wall to the posterior uterine wall without hysterotomy. ${ }^{5,17} \mathrm{~A}$ transverse cervicoisthmic suture can also be placed if needed to control bleeding from the lower uterine segment. Pereira et al described a technique in which a series of transverse and longitudinal stitches of a delayed absorbable multifilament suture are placed around the uterus via a series of bites into the subserosal myometrium, without entering the uterine cavity. ${ }^{16}$ Two or three rows of these sutures are placed in each direction to completely envelope and compress the uterus. Cho et al described another technique, where multiple square sutures using a straight number 7 or 8 needle and number 1 chromic catgut is used to approximate the anterior and posterior uterine walls. ${ }^{12}$ The U-type suture was described by Hackethal et al, where the needle was inserted at the ventral uterine wall, led through the 
posterior wall, and then passed back to the ventral wall where the thread was joined with a flat double knot. ${ }^{5}$

The success rate of uterine compression sutures has been reported to be 77 to $82 \%$ in several case series. Price and B-Lynch presented a detailed review of 15 published reports, which included 46 cases with two failures. ${ }^{18}$

Baskett described the largest series of 28 cases, in which hysterectomy was avoided in 23 patients. ${ }^{19}$ Wohlmuth et al described 22 cases: 11 cases obtained hemostasis with the B-Lynch suture alone and six cases with the suture and uterine and/or ovarian artery ligation. ${ }^{20}$ They had a $77.3 \%$ success rate, similar to the 28 cases reported by Baskett, who had an $82.1 \%$ success rate. $^{19}$

In our series of 12 patients, our success rate was $92 \%$, which is comparable to previous reports, with one case requiring a hysterectomy. Though the evidence for the use of compression sutures is based on case series without proper control groups, it is apparent that uterine compression sutures are successful in most of the cases and should be incorporated or even be the first-line surgical treatment for $\mathrm{PPH}$ due to uterine causes. When PPH due to uterine atony appears during cesarean section and does not respond to medical treatment, it is reasonable to perform compression sutures before the patient's condition deteriorates and hemodynamic decompensation occurs. In our series, we identified four patients who were treated by compression sutures after relative mild $\mathrm{PPH}$ of $\sim 1.2$ to $1.9 \mathrm{~L}$. Because it was reported that obstetricians tend to underestimate blood loss during delivery, ${ }^{3}$ we speculate that the actual blood loss was likely higher and therefore surgical intervention was indicated.

$\mathrm{PPH}$ after vaginal delivery is treated somewhat differently with the intention to prevent surgical interventions if at all possible. Transcervical placement of an intrauterine balloon may achieve intrauterine pressure without surgery. However, if an intrauterine balloon is unavailable or unsuccessful, then uterine compression sutures can be performed within a short period of time even by physicians who have no previous experience with performing the technique.

Although uterine compression sutures appear to be effective in treating $\mathrm{PPH}$, there are known complications following their use. $\mathrm{Wu}$ and $\mathrm{Yeh}^{21,22}$ reported uterine synechiae formation following square sutures, which were visible at hysteroscopy 2 years after the procedure. This may have been caused by use of delayed absorbable suture (1-0 dexon polyglycolic acid suture). Ochoa et $\mathrm{al}^{23}$ reported development of pyometra following square sutures in a case of chorioamnionitis. The patient presented 4 weeks postpartum with fever and an enlarged uterus filled with infected lochia. Two other instances of uterine necrosis following B-Lynch sutures have also been reported. Dadhwal et $\mathrm{al}^{24}$ reported a patient presenting 4 months postpartum with cramping due to development of hematometra, which collected between the Cho sutures. Akoury and Sherman ${ }^{25}$ described a case from our center in which a B-Lynch compression sutures were complicated by subsequent myometrial necrosis. However, this patient had two uncomplicated subsequent pregnancies and caesarean section at term of two healthy babies.

Health care providers should be aware of the possible complications associated with compression sutures, and patients treated by uterine compression sutures should have long-term follow-up postoperatively to ensure early identification of complications. The reported complications of uterine compression sutures were mainly after using the B-Lynch technique or the Cho square sutures. Therefore, we suggest using the simple U sutures as the method of choice for uterine compression sutures. This kind of suture is relatively easy to perform, does not distort the uterine shape, and does not form closed space inside the uterus. Our case series, as with previous case series, is limited because there is no comparison to a control group. However, uterine compression sutures in our cases were the only available treatment before other surgical interventions or hysterectomy, and therefore we believe that uterine compression sutures are efficient in controlling $\mathrm{PPH}$.

In summary, in our experience uterine compression sutures were an effective treatment for $\mathrm{PPH}$ with a success rate of over $90 \%$. The complications of uterine compression sutures are probably more common with the B-Lynch and Cho techniques, and therefore a simple U-shaped sutures appears to be the method of choice. Early identification of $\mathrm{PPH}$ and immediate treatment by both conservative and surgical procedures such as uterine compression sutures are the key to successful treatment and prevention of hemodynamic shock and its consequences.

\section{ACKNOWLEDGMENTS}

Nihal Al Riyami designed the study, performed the study, collected the data, and drafted the manuscript. Dini Hui participated in collecting the data. Elaine Herer participated in designing the study. Ori Nevo designed the study and participated in drafting the manuscript.

\section{REFERENCES}

1. Lu MC, Fridman M, Korst LM, et al. Variations in the incidence of postpartum hemorrhage across hospitals in California. Matern Child Health J 2005;9:297-306

2. Mousa HA, Alfirevic Z. Treatment for primary postpartum haemorrhage. Cochrane Database Syst Rev 2003;(1): CD003249

3. Stafford I, Dildy GA, Clark SL, Belfort MA. Visually estimated and calculated blood loss in vaginal and cesarean delivery. Am J Obstet Gynecol 2008;199:519, e1-e7 
4. Ueland K. Maternal cardiovascular dynamics. VII. Intrapartum blood volume changes. Am J Obstet Gynecol 1976; 126:671-677

5. Hackethal A, Brueggmann D, Oehmke F, Tinneberg HR, Zygmunt MT, Muenstedt K. Uterine compression U-sutures in primary postpartum hemorrhage after cesarean section: fertility preservation with a simple and effective technique. Hum Reprod 2008;23:74-79

6. Jacobs AJ, Lockwood CJ, Barss VA. Causes and treatment of postpartum hemorrhage. Obstet Gyn 2008;16:1-3

7. Combs CA, Murphy EL, Laros RK Jr. Factors associated with postpartum hemorrhage with vaginal birth. Obstet Gynecol 1991;77:69-76

8. Dildy GA III. Postpartum hemorrhage: new management options. Clin Obstet Gynecol 2002;45:330-344

9. Prendiville W. Active versus expectant management of third stage of labour. Lancet 1998;351:1659; author reply 1660

10. Prendiville WJ, Elbourne D, McDonald S. Active versus expectant management in the third stage of labour. Cochrane Database Syst Rev 2000;(3):CD000007

11. B-Lynch C, Coker A, Lawal AH, Abu J, Cowen MJ; C BL. The B-Lynch surgical technique for the control of massive postpartum haemorrhage: an alternative to hysterectomy? Five cases reported. Br J Obstet Gynaecol 1997;104:372-375

12. Cho JH, Jun HS, Lee CN. Hemostatic suturing technique for uterine bleeding during cesarean delivery. Obstet Gynecol 2000;96:129-131

13. Doumouchtsis SK, Papageorghiou AT, Arulkumaran S. Systematic review of conservative management of postpartum hemorrhage: what to do when medical treatment fails. Obstet Gynecol Surv 2007;62:540-547

14. Allam MS, B-Lynch C. The B-Lynch and other uterine compression suture techniques. Int J Gynaecol Obstet 2005; 89:236-241
15. Hayman RG, Arulkumaran S, Steer PJ. Uterine compression sutures: surgical management of postpartum hemorrhage. Obstet Gynecol 2002;99:502-506

16. Pereira A, Nunes F, Pedroso S, Saraiva J, Retto H, Meirinho M. Compressive uterine sutures to treat postpartum bleeding secondary to uterine atony. Obstet Gynecol 2005;106: 569-572

17. Ghezzi F, Cromi A, Uccella S, Raio L, Bolis P, Surbek D. The Hayman technique: a simple method to treat postpartum haemorrhage. BJOG 2007;114:362-365

18. Price N, B-Lynch C. Technical description of the B-Lynch brace suture for treatment of massive postpartum hemorrhage and review of published cases. Int J Fertil Womens Med 2005; 50:148-163

19. Baskett TF. Uterine compression sutures for postpartum hemorrhage: efficacy, morbidity, and subsequent pregnancy. Obstet Gynecol 2007;110:68-71

20. Wohlmuth CT, Gumbs J, Quebral-Ivie J. B-Lynch suture: a case series. Int J Fertil Womens Med 2005;50:164-173

21. Wu HH, Yeh GP. Uterine cavity synechiae after hemostatic square suturing technique. Obstet Gynecol 2005;105(5 Pt 2): 1176-1178

22. Treloar EJ, Anderson RS, Andrews HS, Bailey JL. Uterine necrosis following B-Lynch suture for primary postpartum haemorrhage. BJOG 2006;113:486-488

23. Ochoa M, Allaire AD, Stitely ML. Pyometria after hemostatic square suture technique. Obstet Gynecol 2002;99:506-509

24. Dadhwal V, Sumana G, Mittal S. Hematometra following uterine compression sutures. Int J Gynaecol Obstet 2007;99: 255-256

25. Akoury H, Sherman C. Uterine wall partial thickness necrosis following combined B-Lynch and Cho square sutures for the treatment of primary postpartum hemorrhage. J Obstet Gynaecol Can 2008;30:421-424 